\title{
Metrópoles diversas e colônias semelhantes - uma análise crítica da hipótese das transferências institucionais entre metrópoles e colônias
}

Diverse metropolises and similar colonies - a critical analysis of the hypothesis of institutional transfers between metropolises and their colonies

Luiz Paulo Ferreira Nogueról

Universidade de Brasília

\begin{abstract}
The paper presents evidence that the popular concept of institutional transfers between metropolis and colonies, derived from Douglass North's theories, are not always true. For this purpose, we made use of documents elaborated during the periods of Spanish, Portuguese, and Dutch rule in Brazil and Argentina to show that, in spite of the diversity of metropolises, the colonies ended up buiding similar institutions.
\end{abstract}

\section{Keywords}

new institutional economics; colonialism.

JEL Codes O54; N16.

\section{Resumo}

O artigo apresenta evidências de que a concepção comum sobre as transferências institucionais entre metrópoles e colônias, com base em Douglass North, não é sempre verdadeira. Para tanto, fez uso de fontes primárias argentinas, obtidas no Archivo General de La Nación, do Brasil Holandês, publicadas pela Companhia Editora de Pernambuco, e de Salvador às vésperas da Independência, de autoria do desembargador João Rodrigues de Brito. Verificou-se que, apesar da diversidade das metrópoles, as colônias possuíam instituições semelhantes.

\section{Palavras-chave}

nova economia institucional; colonialismo.

Códigos JEL O54; N16. 


\section{Introdução}

Em 1993, Douglass North foi laureado com o Prêmio Nobel de Economia. Historiador e economista longevo, teve o estudo do desenvolvimento econômico entre as principais preocupações acadêmicas ao longo da vida. Autor de teorias originais sobre as pré-condições que permitiram às sociedades industriais atingir níveis de renda e bem-estar social elevados, relacionou a performance econômica que têm a eventos remotos e a processos retroalimentadores que favoreceram a construção de ambientes econômicos propícios ao funcionamento de mercados eficientes, caracterizados por custos de transação pequenos e pela impessoalidade, dentre outras coisas.

Como contracara ao desenvolvimento econômico, North apresenta casos em que a performance econômica e social não foi auspiciosa, criando-se sociedades parcialmente predadas por elites econômicas que logram se apropriarem de parte do produto econômico criado por outros, ${ }^{1}$ por mecanismos legal e tradicionalmente estabelecidos. Isso possui dois efeitos deletérios graves: por um lado, desestimula as atividades econômicas produtivas e, por essa via, o crescimento econômico, e, por outro lado, reforçam-se as instituições existentes, impedindo o surgimento de situações e circunstâncias distintas e melhores, porque geradoras de níveis de renda maiores.

Como exemplo de sucesso, North menciona os Estados Unidos, que teriam herdado dos colonizadores britânicos as instituições favoráveis ao desenvolvimento de mercados impessoais e com baixos custos de transação. Como contraposição à elevada renda per capita e aos elevados níveis de bem-estar social norte-americanos, tem-se a América Latina, possuidora de uma espécie de herança maldita legada pelos colonizadores ibéricos, os quais seriam oriundos de sociedades com elevados custos de transação e com mercados poucos desenvolvidos. ${ }^{2}$

1 "But so, too, can unproductive paths persist. The increasing returns, characteristic of an initial set of institutions that provide disincentives to productive activity will create organizations and interest groups with a stake in the existing constraints. They will shape the polity in their interests. Such institutions provide incentives that may encourage military domination of the polity and economy, religious fanaticism, or plain, simple redistributive organizations, but they provide few rewards from increases in the stock and dissemination of economically useful knowledge". (North, 1990, p. 99)

2 "The divergent paths established by England and Spain in the New World have not converged despite the mediating factors of commom ideological influences. In the former, an institutional framework has evolved that permits the complex impersonal exchange necessary to political stability and to capture the potential economic gains of modern thecnology. In the latter, personalistic relationships are still the key to much of the political and economic exchange. They are a consequence of an evolving institutional framework that produces neither political stabililty nor consistent realization of the potential of modern 
No presente artigo, são apresentados três casos de instituições coloniais em funcionamento tendo por base fontes primárias, ${ }^{3}$ sendo o primeiro de Buenos Aires, o segundo de Salvador, na Bahia, e o terceiro do Brasil Holandês, com o objetivo de ilustrar que, apesar das diferenças institucionais existentes entre as metrópoles, as colônias desenvolveram-se de maneira semelhante, favorecendo a formação de privilégios e de monopólios característicos do colonialismo primevo, ${ }^{4}$ fortemente influenciado pelo mercantilismo em voga em toda a Europa e, portanto, impedindo a formação de mercados impessoais com baixos custos de transação.

Isso matiza as afirmações comumente feitas sobre as raízes do atraso econômico e social latino-americano valendo-se de Douglass North, mas nem sempre de autoria dele. De fato, neste artigo não se negam as transferências institucionais entre metrópoles e colônias, mas se aponta também para as transferências de colônias para colônias, para o desenvolvimento de instituições coloniais ausentes nas metrópoles e enfatiza-se ainda a diferenciação institucional entre colônias de uma mesma metrópole.

technology". (North, 1990, p. 117)

3 As fontes primárias empregadas para a redação deste artigo encontram-se quase todas publicadas, como indicado na bibliografia. A Companhia Editora de Pernambuco reeditou, por ocasião da passagem dos 350 anos do fim da presença holandesa no Brasil, vários livros sobre o assunto, incluindo-se uma seleção de documentos obtidos em arquivos holandeses por José Antônio Gonsalves de Mello, que os traduziu. A resposta do desembargador João Rodrigues de Brito à Câmara de Vereadores, de Salvador, foi publicada como livro em 1821, em Lisboa, provavelmente como reflexo da Revolução do Porto, que pretendia pôr fim ao Antigo Regime em Portugal. Ela se encontra disponível no Google Books. Os manuscritos lidos em Buenos Aires foram disponibilizados pelo Archivo General de La Nación - Argentina e se encontram reunidos na parte Comercio e Padron de Escravos, a qual reúne vários documentos concernentes ao tráfico de escravos para o Prata e à contagem, para fins fiscais e censitários, de negros e de escravos na região. Encontrar os documentos platinos foi mera questão de sorte, dados os objetivos da pesquisa, voltados para o estudo da participação de traficantes brasileiros no fornecimento de escravos para o local. Quanto aos documentos brasileiros, o acesso a eles foi igualmente casual: em uma viagem ao Recife, tive conhecimento da coleção da Companhia Editora de Pernambuco. Em relação ao documento de autoria do desembargador, ele foi mencionado pelo professor Fernando Novais em uma das aulas do Programa de Pós-Graduação em Economia Aplicada no Instituto de Economia da Unicamp, em 2000. A convivência com meus colegas da Faculdade de Ciências Econômicas da Universidade Federal do Rio Grande do Sul motivaram-me a confrontar, por meio deste artigo, algumas concepções por eles expressas com base em Douglass North.

4 A colonização das Américas não se fez com as mesmas instituições dos Descobrimentos ao século XIX. Assim, por exemplo, o surgimento de companhias privilegiadas dominando colônias é fenômeno do século XVII em diante e foi mais marcante nos casos inglês e holandês; o monopólio comercial das metrópoles sobre as colônias ora foi maior, ora foi menor, dependendo das metrópoles e das colônias em questão. Chamo de colonialismo primevo ao que se instituiu ainda no século XVI, favorecendo os monopólios comerciais, o trabalho compulsório e, de modo geral, as instituições do Antigo Regime comuns à maior parte da Europa Ocidental. 


\section{Dois casos de práticas mercantilistas no final do período colonial - Buenos Aires e Salvador}

Em primeiro de dezembro de 1794, Don Tomás Antonio Romero, natural da cidade de Moguez, no Reino de Sevilha, apresentou ao vice-rei Nicolas de Arredondo, em Buenos Aires, uma memória ressaltando o papel que desempenhara como o primeiro negreiro do vice-reino do Rio da $\operatorname{Prata}^{5}$ a fazer, diretamente, o tráfico de escravos com a África. ${ }^{6}$

Para tanto, afirmou ter adquirido um casco de navio abandonado em Montevidéu, o qual foi reformado e adaptado ao comércio negreiro transformando-se na fragata La Mogueseña.

Con ese buque, con el dinero y fructos que embarcó para la compra de negros, y con los demás gastos de la expedición que (sic) se hizo a la vela en 14 de agosto del mismo año de 92, puede decir que arrojó a los perigos de un mar como el de África, y de un negócio para el cual no contaba con factoría ni con corresponsal alguno en aquellos parajes que se lo facilitase... ${ }^{7}$

Da primeira viagem, iniciada no Prata, ele teria obtido 542 africanos, tendo desembarcado 426 sobreviventes em Buenos Aires. Com os resultados animadores da primeira expedição, optou por armar uma segunda, a qual não se concretizou porque fora dada a notícia da guerra com a França e ele temia que a embarcação fosse capturada por corsários no Atlântico Sul.

Optou, então, por desfazer-se da fragata La Moguerseña, escolhendo Cádiz (Espanha) como local de venda e nomeando, no porto castelhano, um procurador autorizado a vendê-la. Ocorreu, então, que:

[...] hallabase en ese estado medio, de desconfianza por una parte y, por otra, de esperar una nueva conyuntura, cuando llegó la real orden del 7 de octubre de 93 en que proviene el Rey a V.[osa] E.[xcelencia] se diesen gracias al expoente

5 O Vice-Reino do Rio da Prata foi instituído em 1776 a partir do desmembramento do Vice-Reino do Peru. Ele englobou a maior parte dos territórios atuais do Uruguai, do Paraguai, da Argentina e da Bolívia e tinha Buenos Aires como capital.

6 A presença de escravos onde posteriormente seria estabelecido o Vice-Reino do Rio da Prata data pelo menos do século XVII (Studer, 1984). A acreditar no traficante, antes dele não se fazia o tráfico diretamente com a África. Ao que parece, dependia-se dos fluminenses. Segundo Alencastro (2000, p. 201), Salvador de Sá e Benevides, ao mesmo tempo governador do Rio de Janeiro e encomendero em Tucumán, era um dos mais ativos negreiros a fazer a rota Luanda - Rio de Janeiro - Buenos Aires - Alto Peru no Seiscentos. Uma lembrança prosaica de tal atividade é dada pelo culto de Nossa Senhora de Copacabana no Rio de Janeiro, santa de origem andina, atualmente padroeira do exército boliviano, com santuário estabelecido em Copacabana, cidade às margens do Lago Titicaca, onde, em tempos pré-colombianos, se cultuava outra divindade.

7 Cf. Memória de Don Tomás António Romero: Archivo General de La Nación - Argentina, Sala IX, 18-8-61, División Colônia - Sección Gobierno - Comércio y Padrones de Esclavos. 
[Don Tomás António Romero] por la expedición executada de que se habló en princípio, y se le animase a que emprendiese otras.

O que foi suficientemente persuasivo: o traficante desistiu de vender o barco. Ao mesmo tempo, o apoderado (procurador) que se encarregara de vendê-lo em Castela, sem saber da volubilidade de Don Tomás Antonio Romero, optou não apenas por comprá-lo, como a carregá-lo com mercadorias e a enviá-lo de volta a Buenos Aires visando vendê-las no porto platino, provavelmente por intermédio do negreiro.

Em razão do incentivo inesperado advindo do rei e da decisão de dar continuidade ao negócio em que se metera, Don Tomás Antonio Romero solicita então ao vice-rei do Rio da Prata, Nicolas de Arredondo, três graças:

1. que se anulasse a venda da fragata, realizada em Cádiz, para e pelo procurador de Don Tomás António Romero, a fim de viabilizar imediatamente novas expedições empregando a La Moguezeña, a qual se encontrava em Buenos Aires carregada com mercadorias advindas da Espanha;

2. que se dispensasse a embarcação de voltar à Espanha entre a venda dos cativos na América, depois da planejada segunda expedição, e um esperado retorno à África para uma terceira e;

3. que o negreiro tivesse o direito de adquirir mais uma embarcação, dessa vez no Caribe, para ser empregada na terceira expedição.

O segundo favor se explica da seguinte forma: apesar dos lucros do tráfico direto entre o Prata e a África, o traficante pretendia, depois de adquiridos os cativos na segunda expedição, vendê-los no Caribe, e não no sul da América do Sul, sendo citadas como destinos, especificamente, as praças mercantis de Santa Fé, de Caracas e de Havana. Em uma das três, a depender da ocasião, ele pretendia adquirir mais um navio negreiro a ser utilizado imediatamente, o que explicaria o terceiro pedido.

A memória de Don Tomás Antonio Romero apresentada ao vice-rei, redigida em terceira pessoa, revela várias práticas sociais e algumas inovações então recém-introduzidas. A inovação em questão é a que consta da Real Ordem de 17 de setembro de 1793, assim como a que consta da Real Cédula de 24 de novembro de 1791, permitindo aos espanhóis o contato direto com a África para fins de tráfico de escravos e isentando os traficantes de vários impostos e de obrigações característicos da época. Uma das práticas, para a qual queremos chamar a atenção, é a da ausência de liberdade de empresa que caracterizou o colonialismo espanhol, causa de elevados custos de transação, como indicado por Douglass North, dentre 
outros autores. ${ }^{8}$ De fato, com a exceção da anulação da venda da embarcação em Cádiz, que poderia ser vista, aos olhos de hoje, como quebra de contrato, as outras duas graças solicitadas ao vice-rei, dispensando o traficante de tocar obrigatoriamente os portos espanhóis entre as viagens da América para a África e solicitando autorização para adquirir uma nova embarcação no Caribe, não teriam razão de ser se houvesse o que hoje se chama liberdade de empresa.

Ocorre que tal falta de liberdade não era exclusividade do colonialismo espanhol. Tomando como exemplo a resposta do doutor João Rodrigues de Brito, desembargador do Tribunal da Relação em Salvador, em 1807, ao Senado da Câmara de Vereadores daquela cidade, ${ }^{9}$ pode-se atestar que a colonização portuguesa também primou pela falta de liberdade de empresa, assim como de outras liberdades. ${ }^{10}$

Em 1807, tendo o governador da Capitania da Bahia, o conde da Ponte, de prestar várias informações ao príncipe regente, Don João, sobre o que hoje chamamos problemas econômicos, enviou ao Senado da Câmara de Vereadores de Salvador um questionário que deveria ser respondido por pessoas escolhidas pelos vereadores. Em síntese, o soberano perguntava se havia algo que obstava a prosperidade do comércio, quais eram as causas de tais obstáculos e o que se poderia fazer para removê-los.

A Câmara de Vereadores escolheu o desembargador para respondê-lo, dentre outras pessoas. Do ponto de vista do historiador do século XXI, foi uma excelente escolha, uma vez que a resposta teve por base as doutrinas liberais então em popularização na Europa, ${ }^{11}$ o que não supunha que as pessoas que as professavam fossem toleradas pelos respectivos governos.

8 Uma boa contextualização do colonialismo espanhol nos primeiros momentos é: Thomas, 2011. Curiosamente, o rei que uniu os tronos de Castela e de Aragão, dando origem à Espanha como Estado unificado, foi Carlos I, neto de Isabel de Castela e de Fernando de Aragão, pelo lado materno, e de Maximiliano I de Habsburgo e de Maria de Borgonha, pelo lado paterno. Ele herdou dos avós tanto a Espanha quanto a Holanda.

9 Cf. Brito, J. R. de: Carta I, In: Brito, J. R. de: Cartas Econômico-Politicas Sobre a Agricultura e o Commercio da Bahia, pelo desembargador João Rodrigues de Brito, Lisboa, I.A.F. Benevides, 1821.

10 Para o caso da criação das instituições da América Portuguesa no Rio de Janeiro, ainda nos século XVI: Cf. Fragoso (2001).

11 "Para (os males) que procedem dos regulamentos o remédio he revogá-los, e o officio deste Senado ficará alliviado da mais enfadonha, e impertinente tarefa, reduzido aos dictames, que exprimio o nosso sábio Doutor José da Silva Lisboa no Capitulo 50 de seus Princípios de Economia Politica, pelas palavras 'deixai fazer, deixai passar, deixai vender'... Nesse artigo, governa melhor quem menos governa". (Brito, 1821, p. 65) 
Consciente dos riscos que corria pela resposta franca que forneceu, porque atribuiu aos interesses dos vereadores e aos da elite colonial os males sobre os quais perguntava o príncipe, ${ }^{12}$ a todo momento Rodrigues de Brito se desculpava enfatizando que apenas respondia ao que fora perguntado. ${ }^{13}$

O desembargador apresenta uma extensa lista dos males presentes na capital e na capitania, dentre os quais são notáveis: a grande quantidade de licenças necessárias ao exercício de qualquer atividade econômica, os elevados custos para obtê-las, a arbitrariedade dos fiscais que as solicitavam e a insegurança das atividades produtivas, incluindo-se as praticadas dentro da lei, pela morosidade dos tribunais. ${ }^{14}$ Assim, por exemplo, apesar de Salvador ser uma cidade diante do mar e de uma extensa baía de onde facilmente se poderiam extrair frutos, os pescadores viam-se constrangidos a aguardar a vez de atracarem no trapiche sob o sol e o calor característicos da Bahia até que fossem feitas as devidas inspeções pelos fiscais disto encarregados nas já atracadas. Dado o pequeno número de funcionários, todos os dias havia perda de pescados porque, sem inspecionar rapidamente todos os barcos, aqueles que ficavam para o dia seguinte, ou por último, perdiam a carga. $\bigcirc$ desembargador suspeitava até da existência de um mercado cuja mercadoria seria ou a leniência dos fiscais ou a maior rapidez no cumprimento do dever, desde que para isso fossem pagos. ${ }^{15}$ Como resultado, a oferta de frutos do mar era menor do que a possível em razão de leis e regulamentos que evidentemente mais atrapalhavam do que ajudavam a população, embora a mesma coisa não pudesse ser dita sobre os ganhos dos funcionários e dos monopolistas, que, por tais métodos, se livravam da concorrência.

12 Por exemplo: "Huma das causas por que este, e outros ramos do governo municipal das terras, se acha no deplorável estado, que he notório a todos, consiste na forma porque se fazem as eleições dos officiaes das Câmeras [...]; porque se não vota por escrutinio secreto, mas sim perante o corregedor da comarca, e seu escrivãos, os quaes fazem as pautas conforme as insinuações, que se thes inspirão, e ainda sem insinuações vem a ficar a eleição no arbitrio de quem apura as pautas; por isto, não admira que o governo das cidades e villas ande monopolizado em poucas familias privilegiadas, onde não he fácil achar homens capazes para o bom governo dos povos, isto he, sábios e virtuosos...". (Brito, 1821, p. 33) 13 "Por isso, julgo desnecessário fatigar mais a VVSS com minhas prolixas declamações, a que ponho enfim termo com a sincera protestação (sic) de que a liberdade, com que tenho declarado minhas opiniões contra alguns regulamentos deste preclaríssimo Senado, não provém de falta de respeito, que lhe he devido, e eu mui especialmente lhe consagro, mas tão somente da consideração de dever...". (Brito, 1821, p. 77)

14 "O systema emmolumentario faz com que todos os empregados na administração da justiça tenhão interesse em multiplicar, prolongar e complicar os processos; porque quanto mais estes se multiplicão, prolongão e complicão, mais crescem as assignaturas para os julgadores, allegações para os advogados, escritas para os escrivães e salários para os solicitadores...". (Brito, 1821, p. 53)

15 Cf. Brito (1821, p. 10). 
Outro exemplo: o fornecimento de carne verde à cidade era um suplício: as boiadas deveriam trafegar por uma única e mesma estrada entre o local de criação e as imediações de Salvador, sendo o caminho desprovido de bons pastos e de pontes e, por isto, a travessia dos rios era feita a vau, ocasião em se perdiam várias rezes em razão da força das águas e da fraqueza dos animais pelo pouco alimento consumido ao longo do caminho. Em Salvador, apenas três ou quatro marchantes estavam autorizados a negociar a compra das boiadas, com o que os preços da carne verde eram por eles manipulados em desfavor dos criadores e dos consumidores. ${ }^{16}$ Por fim, os problemas relacionados com os frutos do mar e com o fornecimento de gado se repetiam com a farinha de mandioca e com todas as outras mercadorias que entravam na cidade, incluindo-se o açúcar, que, para ser produzido em engenhos, deveria contar com as devidas licenças, as quais não eram facilmente obtidas, etc.

Identificados os problemas, o desembargador responsabilizava o próprio Senado da Câmara pela situação, sendo os vereadores os principais beneficiários do regime de escassez forçada a que estavam submetidos os habitantes de uma das maiores cidades da América naquele momento e, com certeza, a segunda cidade mais populosa da América Portuguesa. ${ }^{17}$

O ambiente institucional soteropolitano não aparentava ser substancialmente distinto do buenairense no que toca à manipulação dos mercados por grupos específicos que se relacionavam diretamente com o Estado, ${ }^{18} \mathrm{O}$ que reforça os argumentos de North sobre o uso do Estado para predar a produção privada: em março de 1794, pouco mais de oito meses antes que Don Tomás Antonio Romero brindasse o vice-rei com a memória anteriormente comentada, a Junta de Comércio de Buenos Aires se reuniu para tratar do seguinte problema: os privilégios com que contavam os negreiros, como Don Tomás António Romero, eram tais que, alegava-se, havia enorme prejuízo para os cofres da Coroa espanhola: na hipótese de que se exportassem 250 mil couros como contrapartida à entrada de africanos escravizados, o montante perdido, via isenção fiscal, chegaria a 380.116 pesos e sete e meio reais. Se fossem exportados ainda mais couro em troca de escravos, o prejuízo seria evidentemente maior.

16 Cf. Brito (1821, p. 11).

17 Uma excelente obra sobre o Recôncavo Baiano, no período colonial, é de autoria de Schwartz (1988).

18 Sobre o ambiente econômico e as relações entre o Estado e os grupos privados no Rio da Prata, cf. Prado (2009). 
O zelo pelo erário por parte dos súditos bonaerenses, reunidos na Junta de Comércio, não era dado apenas pelo amor que nutriam pelo rei Carlos IV. Havia, isto sim, uma disputa entre o comerciante recém-chegado, Don Tomás António Romero, e os de mais longa data, os quais ou não participavam do comércio negreiro ou não o admitiam nos termos que as Reais Cédulas o regulavam. De fato, ao conceder incentivos fiscais aos negreiros, os quais se traduziam na isenção de impostos de exportação sobre o couro embarcado como contrapartida pela importação de escravos, causava-se prejuízo aos demais exportadores porque se desequilibravam as condições da concorrência entre o grupo estabelecido havia mais tempo e os adventícios.

Por essa razão, a Junta contestava a aplicação das Reais Cédulas por meio do célebre "obedezcase pero no se cumpla" característico da colonização espanhola: a Junta pugnava pela suspensão da aplicação da vontade real utilizando-se, para tanto, do seguinte argumento: a Real Cédula e a Real Ordem autorizavam a troca dos escravos trazidos diretamente da África por fructos del país com incentivos fiscais. Alegavam os súditos reunidos na Junta que os couros não poderiam ser entendidos como frutos do país. ${ }^{19}$ Por isto, pediam a suspensão até que fossem consultados os órgãos competentes, na Espanha, os quais decidiriam em favor ou contra as alegações apresentadas. Enquanto isso, em razão da conhecida morosidade do aparato colonial, ${ }^{20}$ reequilibrar-se-ia a concorrência em favor dos membros da Junta e em prejuízo dos traficantes.

Os membros da Junta e, em especial, os deputados da Junta, não deviam ser pessoas sem posses e sem poder porque não era comum que fossem nomeadas pessoas nessas condições para órgão colonial tão importante. Por outro lado, Don Tomás António Romero, pelo capital investido, não era pobre. Em outras palavras, a disputa entre a Junta e o negreiro era uma disputa interna à elite econômica e, possivelmente, social buenaerense, razão pela qual havia motivos para que cada parte sentisse medo da outra. ${ }^{21}$

19 Sem dúvida, um argumento que beirava o absurdo porque, desde o século XVI, as exportações de couro, obtido das imensas boiadas descendentes dos animais introduzidos nos pampas pelos conquistadores, eram características da região. Aparentemente, os membros da Junta pretendiam apenas ganhar tempo enquanto não encontravam argumento melhor para suprimir a concorrência do negreiro.

20 Elliot (1998) usa a expressão "cadeia de papel" para resumir o modo pelo qual as autoridades espanholas logravam submeter os funcionários reais nas Américas, apesar da distância, da demora das comunicações e, principalmente, dos entraves que a legislação espanhola dos séculos XVI e XVII impunha.

21 Sobre a transformação da elite bonaerense de mercantil, no período colonial, para terrate- 
O medo que sentiam os membros da Junta de Comércio em relação a Don Tomás António Romero pode ser verificado pela troca de missivas entre ele, os deputados da Junta, o vice-rei e o apoderado del Commércio, Don Martin de Sarratea, o qual fora instado, em 4 de abril de 1794, nos seguintes termos: "Que exprese por sus nombres los indibiduos que foran citados por la expresada Junta y no concurriran a ella..." (Sobre la Inteligência..., p. 13). Em resposta, três dias depois, foi apresentada a lista. No dia 11, em nova missiva ao vice-rei Nicolas de Arredondo, o negreiro quis saber quem convocara a reunião e aqui se manifestaram os temores dos membros da Junta em relação ao traficante. Em uma primeira resposta enviada a Romero, datada de 23 de abril, respondeu-se que a convocatória fora feita por Sarratea, que, pelo ofício de deputado do comércio, era a quem cabia a convocação formal. Ocorre que, como o próprio Sarratea fez questão de explicar no mesmo dia ao vice-rei, a ideia não partira dele, sendo ele apenas o instrumento de convocação, mas não o idealizador do ato. Em seguida, ainda em 23 de abril, Don Joseph Martinez de Hoz, Don Jaime Alcina e Don Diego de Aguero contestaram a pretensão do vice-rei não apenas de informar ao traficante quem teve a ideia de convocar a Junta, mas também o conteúdo das decisões tomadas. Alegavam que, como deputados da Junta, não haviam sido citados para pronunciarem-se a respeito do que fora pedido, motivo que consideravam suficiente para negar ao negreiro as informações solicitadas.

A Junta de Comércio de Buenos Aires, formada por comerciantes da capital do vice-reino, reuniu-se para estabelecer meios a partir dos quais impedir que Don Tomás Antonio Romero levasse couros do Prata para Sevilha e para quaisquer outros portos sem pagar os impostos a que estavam sujeitos os demais comerciantes. Mais do que a defesa da concorrência, que poderia ser cogitada em razão da defesa da igualdade de condições entre os concorrentes, a Junta pretendia o contrário: impedir que a demanda por couro sofresse uma abrupta elevação pela participação dos traficantes de escravos como demandantes, elevando-se os preços do produto que compravam localmente dos criadores de gado e, consequentemente, reduzindo-se os lucros dos comerciantes tradicionais.

No mundo colonial, os principais mercados, isto é, os que podiam proporcionar mais lucros, eram objeto de cuidadosa regulamentação pela Co- 
roa, que sabia fazer o seguinte jogo com as elites das diferentes cidades das Américas: o rei tinha conhecimento que não seria obedecido se não negociasse os termos da obediência com quem deveria obedecê-lo. No entanto, fingia que a simples expressão da vontade real, por meio de um ou de mais de um dos diferentes instrumentos jurídicos com que contava, seria suficiente. As elites coloniais, por outro lado, eram inteiramente conscientes da ficção jurídica em questão e, se unidas, tinham ciência de que poderiam reverter o que lhes fosse desfavorável, desde que agissem de modo hábil, no que se incluía a hipocrisia para não melindrar o rei e provocar reações desnecessárias e daninhas aos interesses locais. A regulamentação mercantil, nesse contexto, era vital para os mercadores coloniais porque a entrada e a saída de ramos de negócio não dependiam somente da habilidade de cada empresário de lidar com as condições impessoais estabelecidas pelo mercado, mas também das relações mantidas com as autoridades coloniais e metropolitanas. Eram tais relacionamentos, dentre outros motivos, que impossibilitavam a existência de mercados impessoais e criavam elevados custos de transação, os quais eram importantes também para afastar a concorrência e para predar a riqueza alheia.

\section{0 peso da História na performance econômica para a nova economia institucional}

A longa resposta do doutor Rodrigues de Brito e os documentos relativos às disputas internas à elite mercantil buenairense parecem dar razão aos que alegam que parte do atraso econômico latino-americano é por causa das instituições herdadas dos ibéricos.

Alguns anos antes que fossem produzidos os relatos expostos na sessão anterior, Adam Smith afirmava que maior prosperidade poderia ser alcançada se fosse dada liberdade aos trabalhadores, aos empresários e aos proprietários de terras para que empregassem os recursos que detinham segundo achassem mais conveniente. Revolucionário para a época, o pensamento de Smith se consubstanciou, em linhas gerais, em instituições formais e informais que, ao longo do tempo, se firmaram, logrando transformar-se em uma nova ordem natural das coisas, razão pela qual, para alguns leitores, os relatos advindos de Buenos Aires, de 1794, e de Salvador, de 1807, causam alguma estranheza e dão razão a North. 
De fato, no que respeita ao desenvolvimento econômico ocidental, North e Thomas (1973) apresentam a seguinte argumentação:

1. o Ocidente diferenciou-se do restante da humanidade por ter sido a primeira região do mundo a escapar das tenazes malthusianas, que produziram ciclos demográficos com as seguintes características: à abundância relativa de terras, em comparação com a população, correspondia uma fase de aumento populacional. Esse chegava ao fim quando tal abundância relativa se reduzia substancialmente pelo crescimento demográfico, iniciando uma situação de menor disponibilidade nutricional para a população europeia. Por fim, a fome se associava a pestes que levavam a mortandade a reduzir o número de europeus, dando início a um novo ciclo;

2. escapar da fome, em alguns lugares da Europa, foi possível muito antes de a Revolução Industrial passar a incorporar novas tecnologias ao sistema produtivo, elevando a produtividade de todos os fatores de produção e do trabalho em particular;

3. duas regiões da Europa escaparam das tenazes malthusianas antes das outras: os Países Baixos e a Inglaterra, o que North e Thomas (1973) atribuem a inovações institucionais que seriam posteriormente, e muito lentamente, exportadas para outras regiões da Europa;

4. tais inovações institucionais criaram melhores técnicas de organização comercial e financeira, fazendo de Londres e de Amsterdã não apenas empórios mercantis onde uma grande variedade de mercadorias produzidas ao redor do mundo poderia ser encontrada, entretanto mais significativo, onde se localizaram bancos e outras instituições financeiras não apenas pelas economias de escala que a proximidade de umas em relação às outras poderia fornecer, mas também em razão da existência de um ambiente de negócios mais favorável a esse tipo de empreendimento;

5. este ambiente mais favorável, por fim, teria sido involuntariamente criado por circunstâncias fortuitas. De um lado e de outro do Mar do Norte, os Estados holandês e inglês criaram a dívida pública segura, rompendo a tradição das casas reais europeias. Controlados os respectivos governos por parlamentos formados, dentre outros, por credores das respectivas dívidas públicas, os parlamentares optaram por uma administração que viabilizava o cumprimento das obrigações financeiras estatais;

6. a administração das contas públicas em favor do pagamento dos compromissos da dívida pública permitiu que fossem formadas expectativas mais favoráveis a respeito dos futuros pagamentos, razão pela qual as 
taxas de juros em tais países teriam caído substancialmente em relação às que se praticavam em outras regiões da Europa;

7. por fim, a queda das taxas de juros permitiu que os empresários passassem a usar mais intensivamente o mercado financeiro para as operações corriqueiras e para a realização de investimentos de longo prazo, elevando a relação entre capital e trabalho para níveis desconhecidos e, desta forma, viabilizando o aumento da remuneração dos trabalhadores, o que permitiu que escapassem da fome, tornando-os mais resistentes às pestes e impedindo-se novas regressões demográficas, como as que ainda ocorreriam em determinadas regiões da Europa no século XVII e, particularmente, na Espanha.

Posteriormente aos argumentos referentes ao nascimento do Ocidente, de autoria de North e Thomas (1973), North (1990) se debruçou sobre as razões do desenvolvimento econômico norte-americano. Para ele, os Estados Unidos, com a Convenção de Filadélfia e com a Constituição de 1788, lograram recriar, nas Américas, condições semelhantes às existentes na Inglaterra e na Holanda: limitou-se a ação do Estado no que tocava à capacidade de expropriação da coisa privada, em geral, e no que respeitava ao não reconhecimento da dívida pública, em particular. Especificamente, a constituição norte-americana afirma no artigo VI: "Todas as dívidas e compromissos contraídos antes da adoção desta Constituição serão tão válidos contra os Estados Unidos sob o regime desta Constituição, como o eram durante a Confederação".

A segurança jurídica dada pela letra da lei à dívida pública tornou as taxas de juros baixas nos EUA, permitindo o desenvolvimento de um mercado financeiro capaz de financiar diversas atividades produtivas, tal como ocorrera anteriormente na Inglaterra e na Holanda. Com isso, uma ex-colônia estabeleceu as bases do desenvolvimento econômico que a transformariam no país mais rico do mundo no século XX, caminho que não foi trilhado pela América Latina.

A explicar as diferentes performances econômicas dos Estados Unidos e da América Latina, North aponta para a História como campo de saber que pode contribuir para entender o fenômeno: cada parte da América teria sido colonizada por metrópoles distintas, com instituições específicas que levaram, posteriormente, à criação de incentivos econômicos distintos. Os latino-americanos teriam adquirido dos colonizadores ibéricos, sem que o soubessem, as instituições do subdesenvolvimento, ao passo que os norte- 
-americanos teriam adquirido, também sem terem consciência das consequências futuras, as instituições do desenvolvimento. ${ }^{22}$

\section{Instituições e elementos da colonização holande- sa no Brasil e no Caribe - casos de um colonialismo primevo}

Como negar a força do passado na determinação do presente? Não se afirmava, até pouco tempo atrás, que os mortos se agarram aos vivos, limitando-lhes a liberdade de movimento, e que a sociedade presente herdou elementos de sociedades passadas sem disso ter consciência ${ }^{23}$

A argumentação de North e Thomas (1973) a respeito do nascimento do Mundo Ocidental parece bastante razoável: a riqueza, que caracterizou o Ocidente no século XX, teria sido fruto não apenas da Revolução Industrial, que pela introdução de outras tecnologias teria elevado consideravelmente a produtividade dos fatores de produção. Antes dela, e viabilizando-a, teria havido uma espécie de revolução institucional, no século XVII, que teria tornado funcionais os mercados financeiros, permitindo que financiassem as atividades produtivas em geral.

Uma das instituições mais importantes dos mercados financeiros, nascida no limiar do século XVII, foi a Bolsa de Valores de Amsterdã, a primeira do mundo. A primeira companhia a emitir ações foi a Companhia Holandesa das Índias Orientais. Note-se que os mercados de ações se formaram paralelamente à administração segura das dívidas públicas, sendo a Bolsa um recinto em que se negociavam tanto papéis públicos quanto privados.

Qual era o negócio da Companhia Holandesa das Índias Orientais? A venda, na Europa, de especiarias adquiridas por pirataria. Os navios da empresa aguardavam o retorno, rumo à Europa, das embarcações portu-

22 Uma evidente falha do argumento de que as colônias necessariamente herdam as instituições das metrópoles, o que North não afirmou mas normalmente se atribui a ele, diz respeito ao caso das colônias inglesas no Caribe, onde os níveis de desenvolvimento se assemelham aos latino-americanos. Por exemplo, segundo Rabe (2005, p. 3): "At the beginnig of twenty-first century, political, socioeconomic, and epidemiological problems bedevil the people of Guyana. With a per capita income of \$824, it is one of the poorest nations in the Western Hemisphere, ranking just below Paraguay and somewhat above Haiti".

23 Nas palavras de North (2005, p. 83): "It is essential to remember that the constructs humans creates are a blend of 'rational' beliefs and 'non-rational' ones (superstitions, religions, myths, prejudices) that together shape the choices that are made". 
guesas que faziam o mesmo negócio, atacando-as para roubá-las e para posteriormente vender o produto do roubo nos mercados europeus.

De fato, a introdução dos holandeses nos negócios coloniais se fez com uma inovação que escapou aos portugueses: ao constituírem uma companhia por ações, como a Companhia Holandesa das Índias Orientais (VOC), obtiveram algumas vantagens que praticamente sepultaram o monopólio português de fornecimento de especiarias para a Europa. ${ }^{24}$ As ações possibilitavam que poupanças diminutas e dispersas fossem reunidas em uma grande companhia que, atuando sob comando unificado, racionalizava as estruturas e resultava em lucros maiores, além de maior capacidade militar ofensiva.

Seguindo o exemplo e o sucesso da Companhia Holandesa das Índias Orientais, em 1624 é fundada a Companhia Holandesa das Índias Ocidentais (WIC). Em 1625, Salvador é capturada, sendo expulsas as tropas mercenárias em menos de doze meses por uma armada espanhola. ${ }^{25} \mathrm{Em} 1630$, o foco da Companhia foi Olinda, inicialmente, e, posteriormente, toda a América Portuguesa, não se descartando a possibilidade de conquista do Prata, visto como entrada para as minas de prata do Alto Peru. ${ }^{26}$

A WIC logrou capturar parte do litoral do Nordeste do Brasil, do atual território de Alagoas ao Ceará. O objetivo era dominar a área produtora de açúcar e tornar-se fornecedora europeia, sem a intermediação portuguesa, o que se logrou temporariamente apesar de alguns percalços.

De fato, o que dirigia a WIC e a VOC eram os lucros que o comércio com as Índias Ocidentais e Orientais poderiam produzir e os preços das ações, aparentemente, variavam de acordo com as notícias advindas do Brasil e do Oriente. Havia também uma difusa interferência política no negócio, uma vez que parte das áreas ocupadas pelas empresas era território português, assim reconhecido havia muito tempo, e, na tentativa de recuperá-lo, o Reino, a partir da Restauração do Trono, em 1640, ora tratava com o governo holandês, ora com as diretorias das Companhias. ${ }^{27}$

24 Além dos holandeses, ingleses e franceses também lutaram para tomar dos portugueses o monopólio das especiarias. Cf. Godinho (1971, vol. IV, p. 209-223).

25 No período, Portugal e Espanha formavam o que a historiografia chamou, posteriormente, de União Ibérica (1580-1640), quando os reis de Espanha eram também reis em Portugal.

26 O que se chamou de Alto Peru, do século XVI ao XIX, corresponde mais ou menos ao atual território boliviano.

27 Por exemplo, segundo Mello (2003, p. 71), uma das possibilidades de resolução dos conflitos com os holandeses em torno do Nordeste contemplava a compra pelos portugueses da 
A conquista militar de Olinda, em 1630, foi relativamente rápida. Os problemas para a WIC se iniciaram depois: tão logo houve a notícia de que os holandeses se encontravam no horizonte, muitos senhores de engenho fugiram como puderam para Salvador, o que foi feito, em muitos casos, a pé, dada a presença holandesa no litoral. Houve quem enterrasse os tachos de cobre e houve também quem estragasse a moenda do engenho, deixando ao conquistador uma espécie de terra arrasada. Na confusão, muitos escravos fugiram e contribuíram, assim, para o engrandecimento do Quilombo de Palmares, localizado na Serra da Barriga, em Alagoas. ${ }^{28}$

Os holandeses se viram, pois, diante de uma espécie de Vitória de Pirro. Se o objetivo da luta era o lucro, a fuga dos senhores de engenho para a Bahia e dos escravos para os quilombos era uma derrota apesar da conquista do território, uma vez que era necessário lidar com a reativação dos engenhos. É verdade que nem todos fugiram, havendo alguns que eram bons conhecedores da arte de produzir açúcar, como João Fernandes Vieira, feitor de um engenho pernambucano à época da invasão holandesa, posteriormente senhor de engenho adquirido em leilão e com pagamento financiado pela própria WIC, herói da Restauração Pernambucana a partir de 1644 e, após a vitória e em reconhecimento pelos serviços prestados ao rei, governador de Angola. ${ }^{29}$

Dado o objetivo de lucrar com a conquista, uma vez assegurado o domínio militar, os dirigentes da companhia em Pernambuco optaram por leiloar os engenhos abandonados, e a lista dos novos proprietários revela que a maioria foi adquirida por luso-brasileiros, sendo que apenas João Fernandes Vieira adquiriu dois. Sem recursos próprios para comprá-los, a WIC financiou as aquisições feitas pelos novos senhores de engenho.

Outro problema não menos grave do que o da reativação dos engenhos e, ao mesmo tempo, parte do problema da produção açucareira, era o do tráfico de escravos. A WIC viu-se às voltas com algo inesperado: a necessidade de conquistar territórios na África a partir dos quais fornecer escravos para o Brasil.

região ocupada pela WIC. Dado o emaranhado de instituições políticas dos Países Baixos, o que tornava as negociações diplomáticas lentas e confusas, aventou-se a compra pela Coroa portuguesa das ações da WIC visando atalhar as negociações intermináveis empreendidas pelos embaixadores portugueses na Haia. Essa opção tinha, porém, o inconveniente de que as companhias emanavam de outorgas do poder público, e, portanto, ainda que a compra do Nordeste e das ações fosse feita, o negócio teria de ser analisado pelo governo dos Países Baixos e poderia ser vetado.

28 Cf. Wätjen (2004, p. 154).

29 Cf. Alencastro (2000, p. 272). 
Dizia-se, no século XVII, que não havia Brasil sem Angola e não havia Portugal sem Brasil, isto é, a riqueza brasileira, o açúcar em primeiro lugar, servia ao sustento do trono português, e a perda do Nordeste, em 1630, foi um grave revés sentido dez anos depois, quando o duque de Bragança liderou uma revolta visando à Restauração do Trono, e as arcas reais encontravam-se vazias para financiar a guerra de independência contra Madri.

Para produzir açúcar com lucros convidativos, eram necessários, além de arrojados empresários como João Fernandes Vieira, escravos, isto é, pessoas forçadas pela violência ao trabalho cotidiano e extenuante. A fim de conseguir escravos na quantidade necessária à produção pernambucana, tornou-se indispensável fazer-se presente nos mercados africanos de escravos, o que a WIC resolveu parcialmente quando tomou dos portugueses, em 1637, o castelo de São Jorge da Mina, construído com material português antes do Descobrimento do Brasil. Dada a insuficiência da oferta de escravos desta região para a demanda brasileira, foram conquistadas Luanda e Benguela, em 1642.

A conquista holandesa de Luanda e de Benguela foi uma decisão pessoal do conde João Maurício de Nassau-Siegen. ${ }^{30} \mathrm{O}$ órgão dirigente da WIC, o Herren XIX, ordenara a conquista de Salvador, visando reduzir ainda mais as possibilidades de ações portuguesas contra Pernambuco. $O$ ilustrado e desobediente conde em Recife, cidade por ele planejada e construída sobre um banco de areia em um delta, revelando talvez preferências holandesas de paisagem, cercado por uma corte formada por botânicos, astrônomos, teólogos, médicos, etc., não refugou as instituições da América Portuguesa: se a companhia queria lucros, antes de conquistar a Bahia era necessário solidificar a conquista pernambucana, e, para tanto, Angola era o complemento necessário. Isso porque, "sem tais escravos não é possível fazer coisa alguma no Brasil: sem eles os engenhos não podem moer, nem as terras ser cultivadas, pelo que necessariamente deve haver escravos no Brasil e por nenhum modo podem ser dispensados: se alguém sentir-se nisto agravado, será um escrúpulo inútil". ${ }^{31}$

Ainda no âmbito das instituições da América Portuguesa, as relações entre o conde e Gaspar Dias Ferreira exemplificavam o tradicionalmente estabelecido: o primeiro protegia o segundo contra as punições pelos cri-

30 Cf. Alencastro (2000, p. 214).

31 Cf. Nassau; Dussen (2004 [1645], p. 108). 
mes que cometia (contrabando de escravos e de outras mercadorias monopolizadas pela WIC), e o segundo dividia com o primeiro os lucros. Ou seja, as relações entre parte da elite local e o Estado, no Brasil Holandês, eram tais que dificilmente poderiam ser distinguidos traços de mercados impessoais e de outras instituições favoráveis à eficiência econômica. ${ }^{32}$

Ao ser demitido do cargo de dirigente dos negócios da WIC no Nordeste, o conde deixou conselhos, que, se tivessem sido seguidos, provavelmente teriam preservado o Brasil Holandês. Ele sugeriu que a Companhia agisse com muita cautela em relação aos endividados senhores de engenho, uma vez que cobrar o que deviam na conjuntura de então poderia causar revoltas. De fato, a companhia não foi suficientemente habilidosa, e o princípio da revolta que conduziu à Restauração Pernambucana coincidiu com a cobrança de créditos vencidos dos senhores de engenho, sendo João Fernandes Vieira, ao mesmo tempo, um dos maiores endividados, um dos maiores senhores de engenho da região e um dos principais líderes do movimento iniciado em $1644 .{ }^{33}$

A colonização holandesa no Brasil não reproduziu as instituições criadas na Holanda que serviram para o desenvolvimento econômico, ${ }^{34}$ apesar de a WIC ser produto de inovações financeiras como a Bolsa de Valores de Amsterdã. Pelo contrário, tem-se aqui a continuidade das instituições mercantilistas criadas pelos europeus na Baixa Idade Média, ${ }^{35}$ pelos portugueses nas ilhas atlânticas e oportunamente transferidas para a América Portuguesa a partir de $1530,{ }^{36}$ apesar das vitórias militares que deram ao conquistador holandês a oportunidade de remodelar a sociedade se assim o quisesse, uma vez que contava com o argumento da força.

Nesses termos, o Brasil Holandês seguiu o mercantilismo praticado por uma companhia privilegiada e o binômio latifúndio e escravidão. Mais do

32 Cf. Calado (2004 [1648], vol. I, p. 233-238).

33 "Tudo muda de feição a partir do momento em que o front se estabiliza, quando o sequestro dos engenhos luso-brasílicos pelos credores holandeses se afigura mais provável que os estragos da guerra. [...] Desse ponto de vista, a revolta anti-holandesa nordestina se apresenta como um levante promovido por um bando de caloteiros. Disse-o ali na bucha o padre Antônio Vieira, num parecer encomendado pela Coroa em 1648: 'Os principais [moradores] que a moveram [a guerra contra a WIC em Pernambuco] foi porque tinham tomado muito dinheiro aos holandeses, e não puderam, ou não quiseram pagar'”. (Alencastro, 2000, p. 218) 34 Segundo North (2005, p. 134): "And it was in the Netherlands and Amsterdam specifically that modern economic growth had its genesis".

35 Cf. Heckscher (1983).

36 Cf. Schwartz (1988, cap. 1 a 3). 
que isso, ele em nada alterou as relações de poder características do Antigo Regime e que ainda hoje se apresentam parcialmente entre nós.

O apego da WIC aos termos do Antigo Regime nos trópicos foi tão forte que, diante do avanço luso-brasileiro sobre o Recife, até mesmo a riqueza privada foi desrespeitada, generalizando-se os confiscos, desconhecendo-se os débitos da companhia com particulares - não contribuindo para a formação de uma dívida pública segura - e, grave erro, atrasando-se os salários dos mercenários que compunham o exército da Companhia, o que contribuiria para as vitórias luso-brasileiras, uma vez que se prometia aos mercenários o pagamento dos valores atrasados se houvesse rendição para os sitiantes. ${ }^{37}$

Em outros termos, se é verdade que o Ocidente nasceu, como querem North e Thomas (1973), na Holanda e na Inglaterra nos séculos XVI e XVII, e se é verdade que as instituições acompanharam os colonizadores, o que North (1990) apresenta como argumento para o atraso latino-americano e para a riqueza norte-americana, então o comportamento ibérico dos holandeses no Brasil deve ser explicado por outros fatores que não a simples transferência institucional porque o governo holandês no Nordeste pouco se distinguiu do português, a não ser no que respeita à inabilidade no trato com as elites coloniais quando da cobrança intempestiva dos débitos dos senhores de engenho com a WIC.

Mais significativo, todavia, foi a reprodução, pelos holandeses, das instituições brasileiras no Caribe: ${ }^{38}$ dada a eminente expulsão do Nordeste, do que decorreu a desvalorização das ações da WIC em Amsterdã ${ }^{39}$ e o quase linchamento do embaixador português na Haia ${ }^{40}$ pela turba multa que perdera dinheiro na Bolsa de Valores (em uma época em que os princípios da imunidade diplomática ainda estavam por serem estatuídos),

37 Por exemplo: "Hoogstrassen aparentou resistir; mas denunciou, por portas travessas, a Vidal o ponto fraco de seu baluarte e induziu os oficiais seus subordinados e a guarnição à entrega do Forte aos portugueses, contra o pagamento dos soldos atrasados - de preferência a sacrificarem suas vidas pela WIC, que tão mal lhes pagava. Montou a 18 mil florins o preço da traição, em virtude da qual Hoogstrassen com a sua gente passou, em 3 de setembro de 1645, ao serviço do adversário, que entretanto nunca lhe conferiu plena confiança". (Wätjen, 2004, p. 239)

38 Concretamente, o Suriname, colonizado pela Holanda, pertenceu à mesma empresa que invadiu e foi dona de Pernambuco entre 1630 e 1654. Lá foram adotadas palavras portuguesas para diferentes fases da produção de açúcar, exemplificando uma transferência institucional de colônia para colônia. Cf. Van Lier (2005, p. 45).

39 Cf. Boxer (1957, cap. IV).

40 Cf. Mello (2003, p. 77). 
optou-se por transferir parte das operações açucareiras para Barbados, então uma possessão inglesa ocupada por pequenos proprietários e colonos sob servidão temporária. ${ }^{41}$

A partir do início das operações da WIC em Barbados, as ilhas do Caribe jamais foram as mesmas: os pequenos proprietários e os colonos europeus sob servidão temporária foram substituídos pelo latifúndio e pela escravidão, sendo a jornada de trabalho dos escravos do sul dos Estados Unidos e do Caribe chamada, em holandês, inglês e francês, de "sistema do Brasil", em referência ao local de onde a instituição fora importada, ${ }^{42}$ apesar da presença dos colonizadores advindos das sociedades europeias que se encontravam na fronteira da revolução institucional que supostamente dera origem ao Ocidente.

\section{Antigo Regime e transferências institucionais}

O termo Antigo Regime, convém lembrar, popularizou-se na esteira das transformações institucionais criadas pela Revolução Francesa e servia para designar uma série de normas e convenções que os novos tempos pretendiam enterrar.

São princípios da Revolução Francesa, em contraposição aos atribuídos ao Antigo Regime, a autodeterminação dos povos, o governo representativo, a liberdade de expressão, a livre-iniciativa, a igualdade jurídica entre as pessoas, excetuados casos especiais de incapacidade civil, etc. Entre tais princípios há coerência: ao se eliminarem os privilégios característicos do Antigo Regime, como manter o direito de determinados particulares sobre o exercício de ofícios e atividades, assim como de monopólios? Do mesmo modo, como manter as colônias e proclamar a autodeterminação dos povos? Como manter a escravidão após a Declaração Universal dos Direitos do Homem e do Cidadão? O pacto colonial, aos olhos da Modernidade, padece de um duplo pecado: fere o princípio de autodeterminação dos povos e ainda cria monopólios. Nesses termos, como mantê-lo?

É evidente que o Antigo Regime não foi sepultado com todas as instituições que o caracterizavam. Assim, por exemplo, apesar de a Assem-

42 Gorender (1988, p. 261). 
bleia Nacional Francesa haver abolido a escravidão nas colônias em 1794, é fato que algumas colônias francesas a mantiveram ou a reestabeleceram oportunamente. Da mesma maneira, a escravidão, atestando as diferenças de Direito oriundas da condição de nascimento, foi mantida nos Estados Unidos até 1865 , apesar de os movimentos abolicionistas norte-americano e britânico apontarem para a incoerência entre a Declaração de Independência, em nome da Liberdade, e a sobrevivência da instituição servil.

O governo submetido a órgãos colegiados eleitos, ainda que os eleitores representassem uma fração da população nacional, é outro elemento que contribuiu para o enterro do Antigo Regime ao suprimir o Absolutismo, o que foi estabelecido, na Holanda e na Inglaterra, ao longo dos séculos XVI e XVII. Vinculado o exercício do voto à cidadania fiscal, estabeleceu-se que o pagamento de tributos dava direito à representação parlamentar, princípio lembrado pelos Pais Fundadores dos Estados Unidos quando da rebelião das colônias inglesas da América do Norte, em 1776.

Douglass North, ao enfatizar a transferência de instituições no período colonial como explicação para o desenvolvimento e para o subdesenvolvimento no século XX, toma o caso norte-americano e o latino-americano como antípodas um do outro. Há que se recordar, no entanto, como fizeram Engerman e Sokoloff (1994), que o desenvolvimento norte-americano é sensivelmente distinto do havido nos Domínios Britânicos no Caribe, ${ }^{43}$ por exemplo.

De fato, muito do que foram as colônias é resultado não apenas de transferências, mas de criação local. Assim, por exemplo, como ignorar a relevância da mita potosina para a grandeza do Peru e da Espanha? ${ }^{44}$

43 "Although many explanations have been offered, this paperhighlights the relevance of substantial differences in the degree of inequality in wealth, human capital and political power in accounting for the variations in the records of growth. [...] Of particular significance for generating extreme inequality were the suitability for the cultivation of sugar and other crops in which there were economies of production in the use of slaves, as well as the presence of large concentrations of native americans. Both of these conditions encouraged the evolution of societies where relatively small elites of Europeans descent could hold highly disproportionate shares of the wealth, human capital, and political power - and stablish economic and political dominance over the mass of the population. Conspicuously absent from the nearly all-inclusive list of New World colonies with these conditions were the British setlements of the northern parts of the North American continent". (Engerman; Sokoloff, 1994, p. 2)

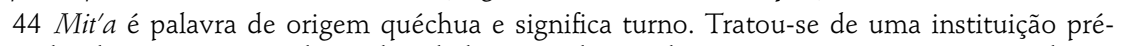
-colombiana por meio da qual os habitantes dos Andes prestavam serviços ao Estado, às etnias e às comunidades (ayllus). No governo do vice-rei Toledo, foi transformada em trabalho compulsório, remunerado a taxas inferiores às praticadas pelos mercados, atribuída a determinadas comunidades em benefício da produção de prata em Potosi e de mercúrio em Huancavellica, dentre outros lugares. Cf. Noejovich (2010, p. 67-87). 
Da mesma forma, ainda que a escravidão tenha existido na Europa, a produção açucareira no Brasil e no Caribe transformou profundamente o que existiu marginalmente nas ilhas mediterrânicas e no sul da Península Ibérica.

Os elevados custos de transação, normalmente atribuídos à colonização portuguesa e espanhola, não são apresentadas como características gerais do Mercantilismo por Heckscher (1983), mesmo em países que não tiveram colônias e que apenas tardiamente comporão Estados-Nações, como a Suécia e a Alemanha?

Por fim, quando Smith (1989) e Ricardo (1988) escreveram, respectivamente, A Riqueza das Nações e Princípios de Economia Política e de Tributação, ao exprobrarem os privilégios de determinados mercadores e as instituições antiliberais da época, no que se incluíam as companhias privilegiadas $^{45}$ reputadas por Smtih como autoras dos piores governos que podia haver, empregavam exemplos ibéricos ou britânicos?

\section{Conclusões}

No início do século XXI, o caminho da prosperidade, objeto de preocupação dos economistas desde antes de Adam Smith, ainda está sujeito a debates e a disputas porque não está estabelecido qual é. Isso se deve a várias razões e, dentre elas, à dificuldade que tem a Economia, como ciência, de seguir o método científico tal como aplicado a campos do saber em que a repetição dos fenômenos é feita em laboratórios.

Por maior que seja a disponibilidade de dados, as sociedades que os produzem são distintas umas das outras, e, mais grave, o comportamento dos agentes se altera com frequência ao longo do tempo. Por isso, nas palavras de North (2005, p. 13): "If we are continually creating a new and novel world, how good is the theory we have develolped from past experience to deal with this new world?"

No caso do desenvolvimento econômico, North e Thomas (1973) apontaram corretamente para a História como campo que pode auxiliar para a compreensão dos problemas. Tomando as primeiras sociedades europeias a se livrarem das tenazes malthusianas, isto é, Inglaterra e Holanda, verificaram que o fenômeno ocorrera muito antes da Revolução Industrial, e isso foi uma importante contribuição ao debate, uma vez que, nos anos 45 A Companhia Holandesa das Índias Ocidentais foi um exemplo de companhia privilegiada. 
60 e 70 do século XX, o modelo de Solow, que relaciona aumento da remuneração dos trabalhadores à acumulação de capital, era tomado como caminho a seguir para a superação do subdesenvolvimento.

North e Thomas (1973), aparentemente com base na crítica dos postulados do modelo de Solow e aproximando-se do modelo de Schumpeter, ${ }^{46}$ argumentavam que é pressuposto para a acumulação de capitais a formação de mercados financeiros, os quais permitem ao empresário captar recursos para empreender novas atividades. Os mercados financeiros, todos sabem, nasceram em determinado momento, e uma espécie de responsabilidade fiscal é entendida pelos autores como pré-condição para tal nascimento, uma vez que reduz as taxas e juros e democratiza o capital.

Necessária, mas não suficiente, para a segurança do pagamento da dívida pública é o controle das finanças públicas, função que coube aos Parlamentos nas sociedades ocidentais, já que se encarregaram da elaboração do orçamento público, no qual se incluem tanto os gastos gerais quanto a administração da dívida pública, e, de fato, foi na Holanda e na Inglaterra que os parlamentos, controlando o endividamento público, viabilizaram a queda das taxas de juros.

O passo seguinte de North (1990), todavia, foi bem mais arriscado: supor a transferência da responsabilidade fiscal da Inglaterra para os Estados Unidos $^{47}$ e, a partir deste caso, a transferência das instituições metropolitanas para as colônias.

O que este artigo procurou demonstrar é que as colônias ora têm instituições próprias, ora importam instituições metropolitanas, como é o caso dos dispositivos mercantilistas comuns a toda a Europa Ocidental nos séculos XV e XVI, ora importam instituições de outras colônias, como no caso do Caribe em relação ao Brasil e do Brasil em relação às ilhas atlânticas portuguesas.

Custos de transação baixos, eliminando-se os entraves desnecessários e voltados para o sustento de parasitas, simplificam a administração das

46 O empresário shumpeteriano não conta necessariamente com recursos para empreender, razão pela qual recorre ao mercado financeiro para conseguir o necessário para iniciar a empresa inovadora ou para introduzir a inovação em uma empresa já existente. Cf. Schumpeter (1988, cap. 3).

47 f fato de que os governos norte-americanos agiram, do ponto de vista fiscal, responsavelmente desde 1776, não supõe que continuarão a fazê-lo: o que dizer do alvoroço criado, nos mercados internacionais, pelas discussões dos últimos anos entre republicanos e democratas acerca da ampliação, ou não, do teto do endividamento federal norte-americano? 
empresas e do Estado ao mesmo tempo que permitem ganhos de produtividade não relacionados com o desenvolvimento tecnológico. Deve-se atentar, todavia, para o fato de que Adam Smith já o indicava como caminho para a riqueza das nações há mais de 200 anos. Tanto essa lembrança feita por Douglass North quanto as contribuições que agregou aos termos propostos por Smith são de grande valia não apenas porque resgatam parte do pensamento do filósofo escocês, como atentam para os pressupostos do desenvolvimento tecnológico: a existência dos mais remotos incentivos para que ele ocorra e, entre eles, dos mercados financeiros.

Infelizmente, porém, a Economia, apesar das contribuições dadas pela História para a compreensão da realidade econômica presente, ainda é um sistema indeterminado: as equações continuam com um número excessivo de variáveis e, igualmente grave, a instabilidade dos parâmetros é recorrente, conformando o que North (2005, cap. dois) chama de mundo não ergódico. Por tais motivos, a procura de uma única causa para o Desenvolvimento Econômico, como a herança colonial, está fadada ao fracasso. Douglass North não afirmou a existência de causas únicas, mas a popularização do pensamento dele entre os economistas brasileiros tem levado a interpretações deste gênero.

\section{Referências}

\section{Fontes manuscritas}

ARCHIVO GENERAL DE LA NACIÓN ARGENTINA. Sobre la Inteligencia que se da por la Junta de Commercio desta Capital a las Reales Ordenes expedidas en favor de Don Tomás António Romero sobre la Introducción de Negros: Sala IX, 18-8-61, División Colônia Sección Gobierno - Comércio y Padrones de Esclavos, 1793.

ARCHIVO GENERAL DE LA NACIÓN ARGENTINA. Memória de Don Tomás António Romero apresentada ao Vice-Rei Nicolas de Arredondo: Sala IX, 18-8-61, División Colônia - Sección Gobierno - Comércio y Padrones de Esclavos, 1794.

\section{Livros e artigos}

ALENCASTRO, L. F. de. O Trato dos Viventes - a formação do Brasil no Atlântico Sul. São Paulo: Companhia das Letras, 2000.

BOXER, C. R. The Dutch in Brazil 1624-1654. Oxford: Clarendon Press, 1957.

BRITO, J. R. de. Carta I. In: BRITO, J. R. de. Cartas Econômico-Politicas sobre a Agricultura e o Commercio da Bahia, pelo Desembargador João Rodrigues de Brito. Lisboa: I. A. F. Benevides, 1821. 
CALADO, M. O Valeroso Lucideno e Triunfo da Liberdade. Recife: Companhia Editora de Pernambuco, [1648] 2004.

ELLIOT, J. H. A Espanha e a América nos séculos XVI e XVII. In: BETHELL, L. História da América Latina, volume 1, América Latina Colonial. São Paulo: Edusp, 1998.

ENGERMAN, S. L.; SOKOLOFF, K. L. Factor endowments, institutions and diferencial paths of growth among new world economies: a view from economic historians of the United States. NBER Working Paper Series on Historical Factors in Long Run Growth, Historical Paper No 66, 1994.

FRAGOSO, J. L. A formação da economia colonial no Rio de Janeiro e de sua primeira elite senhorial. In: FRAGOSO, J.; BICALHO, M. F.; GOUVÊA, M. F. O Antigo Regime nos trópicos. Rio de Janeiro: Civilização Brasileira, 2001.

GODINHO, V. M. Os descobrimentos e a economia mundial. Lisboa: Presença, 1971.

GORENDER, J. O escravismo colonial. São Paulo: Ática, 1988.

HALPERIN DONGHI, T. La formación de la clase terrateniente bonaerense. Buenos Aires: Prometeo, 2007.

HECKSCHER, E. La época mercantilista - Historia de la organización y las ideas económicas desde el final de la Edad Media hasta la Sociedad Liberal. Ciudad de Mexico: Fondo de Cultura Económica, 1983.

KLEIN, H.; VINSON III, B. La esclavitud africana en América Latina y el Caribe. Lima: Instituto de Estúdios Peruanos, 2007.

MELLO, E. C. O negócio do Brasil - Portugal, os Países Baixos e o Nordeste, 1641-1669. Rio de Janeiro: Topbooks, 2003.

NASSAU, J. M.; DUSSEN, A. V. Breve discurso sobre o Estado das quatro capitanias conquistadas, de Pernambuco, Itamaracá, Paraíba e Rio Grande, situadas na parte setentrional do Brasil. In: MELLO, J. A. G. de. Fontes para a História do Brasil Holandês - a economia açucareira. Recife: Companhia Editora de Pernambuco, [1645] 2004.

NOEJOVICH, H. O. La Transición del Sistema Prehispânico al Sistema Económico Colonial. In: CONTRERAS, C. (Ed.). Compéndio de Historia Economica del Perú II: Economía del Período Colonial Temprano. Lima: Banco Central de Reserva del Perú e Instituto de Estúdios Peruanos, 2010.

NORTH, D. C. Institutions, institutional change and economic performance. Nova York: Northon, 1990.

NORTH, D. C. Understanding the process of economic change. Princeton: Princeton University Press, 2005.

NORTH, D. C.; THOMAS, R. P. The rise of Western World: a new economic history. Cambridge: Cambridge University Press, 1973.

PRADO, F. In the shadows of empire: transimperial network and colonial identity in borbon Rio de la Plata (c.1760 - c. 1830). 2009. Tese (Doutorado em História) - Faculty of Graduate School da Universidade Emory, Atlanta, 2009.

RABE, S. G. U.S. Intervention in British Guiana - a cold war history. Kingston: Ian Randle, 2005.

RICARDO, D. Princípios de Economia Política e de Tributação. Lisboa: Fundação Calouste Gul- 
benkian, 1988.

SCHUMPETER, J. A. A Teoria do Desenvolvimento Econômico. São Paulo: Abril, 1988.

SCHWARTZ, S. Segredos Internos. São Paulo: Companhia das Letras, 1988.

SMITH, A. Inquérito sobre a natureza e as causas das riquezas das nações. Lisboa: Fundação Calouste Gulbenkian, 1989.

STUDER, E. F. S. de. La Trata de Negros en el Rio de La Plata. Buenos Aires: Libros de Hispanoamérica, 1984.

VAN LIER, R. A. J. Sociedade de fronteira - uma análise social da história do Suriname. Brasília: Editora da Fundação Alexandre de Gusmão, 2005.

WÄTJEN, H. O domínio colonial holandês no Brasil - um capítulo para a história colonial no século XVII. Recife: Companhia Editora de Pernambuco, 2004.

\section{Sobre o autor}

\section{Luiz Paulo Ferreira Nogueról - luiznoguerol@unb.br}

Professor de História da América no Departamento de História da Universidade de Brasília, Brasília, DF

$\mathrm{O}$ autor agradece ao CNPq por financiar a pesquisa de que resultou este artigo.

\section{Sobre 0 artigo}

Recebido em 8 de agosto de 2014. Aprovado em 27 de fevereiro de 2015. 